\title{
DYNAMIC CHARACTERISTICS OF A MODEL AND PROTOTYPE FOR 3D-RC STRUCTURE
}

\author{
MD. KHAJA MONIUDDIN ${ }^{1 *}$, G. VASANTHALAKSHMI ${ }^{2}$, K. CHETHAN ${ }^{3}$, R. RAMESH BABU ${ }^{4}$
}

\begin{abstract}
Infill walls provide durable and economical partitions that have relatively excellent thermal and sound insulation with high fire resistance. Monolithic infilled walls are provided within $R C$ structures without being analyzed as a combination of concrete and brick elements, although in reality they act as a single unit during earthquakes. The performance of such structures during earthquakes has proved to be superior in comparison to bare frames in terms of stiffness, strength and energy dissipation. To know the dynamic characteristics of monolithic infill wall panels and masonry infill, modal, response spectrum and time history analyses have been carried out on a model and prototype of a 3D RC structure for a comparative study.
\end{abstract}

Address

1 Department of Civil Engineering, B.K.I.T, Bhalki. Karnataka, India.

2 Department of Civil Engineering, KSSEM, Bangalore, Karnataka, India.

3 Department of Civil Engineering, U.V.C.E, Bangalore, Karnataka, India.

4 Additional Director, EVRC, CPRI, Bangalore, Karnataka, India.

* Corresponding author: mdkhajamoniuddin@gmail.com

Key words

- Model

- Monolithic infill,

- Masonry infill.

\section{INTRODUCTION}

A typical multi-storey construction in India is comprised of RC frames with brick monolithic infill (MI). Unreinforced MI wall panels may not contribute towards resisting gravity loads, but do contribute to it significantly, in terms of enhanced stiffness and strength, under earthquake (or wind) induced lateral loading. However, in practice, the stiffness of the infill is commonly ignored in frame analysis, resulting in an under-estimation of its stiffness and natural frequency. Also, MI has energy dissipation characteristics that contribute to improved seismic resistance. It is instructive to study the implications of the common practice of ignoring the stiffness of the infill with regard to performance under seismic loading. Concrete and masonry walls were introduced into the selected frame in order to investigate numerically how important aspects of structural responses such as stiffness, load-carrying capacity, deformation profile, cracking, ductility and the mode of failure of the frame, are affected (P.G. Asteris and D.M. Cotsovos, 2012).

\section{MASONRY INFILL (MI)}

MI is found in most existing concrete frame building systems. These infills have considerable strength and stiffness and have a sig-

nificant effect on the seismic response of a structural system. There is a general agreement among researchers that infill frames have greater strength as compared to frames without an infill. On the other hand, the presence of the infill also considerably increases the lateral stiffness. Due to any changes in stiffness and mass in a structural system, the dynamic characteristics change as well.

\section{DYNAMIC BEHAVIOUR OF MASONRY INFILLED RC FRAMES}

The presence of MI affects the dynamic behaviour of buildings in the following ways:

- As a consequence of any increase in the stiffness of buildings, the fundamental time period is decreased, and the base shear is increased. The lateral stiffness in the plan and elevation is modified.

- The structural system is relieved of seismic action as part of the load is carried by the MI. The energy dissipation capacity of the building is substantially increased.

The more flexible the structural system, the greater the above effects of the infills. It is a common misconception that MI in structural 
steel or RC frames can only increase the overall lateral load capacity. Earthquake damage can be traced to the structural modification of the basic frame by so-called nonstructural masonry partitions and infill panels. MI can drastically alter the intended structural response by attracting forces to parts of the structure that have not been designed to resist them (Paulay and Priestley 1992).

The high degree of uncertainty during analyses of buildings due to the effects of MI includes:

- The variability of their mechanical properties, and hence the low degree of reliability in their strength and stiffness.

- Tightness when connected to the surrounding frame (wedging condition).

- The potential modification of their integrity during the use of the building.

Thus the safety of the structure cannot rely, not even partially, upon the MI, and only its probable negative influence can be taken into account (Md Khaja Moniuddin, 2013).

\section{MONOLITHIC RC PANELS (MW)}

In the past, concrete walls were designed in most structures for protection against the external environment with little consideration for the capability of the wall as a structural member. This approach was mainly due to the very low allowable design stresses for walls specified in early versions of published concrete codes. Doh et al. (2008) conducted laboratory testing on seven walls in a two-way action; the doors were supported on three sides by a small opening, which was symmetrical around the horizontal axis. To supplement these tests, the authors have recently undertaken further testing on six two-way action walls supported by a gable frame and perpendicular to the gable frame with variable opening configurations. For solid walls in a one-way action, Seddon (1956) contributed to the development of the British Standard (BS8110-1997) formula, which is similar to the AS3600-2001 equation. Also, the work of Fragomeni (1995) and Doh (2002) focused on improving the AS3600 equation to include the adopted effective length factors, and broadened its scope to include walls with higher slenderness ratios and higher concrete strengths. On the other hand, Oberlender (1973), Pillai and Parthasarathy (1977), Kripanarayanan (1977), Zielinski et al. $(1982,1983)$ and Saheb and Desayi (1989) have made significant contributions to the development and refinement of the ACI 318 equation. Fragomeni and Mendis (1999) provided a detailed review of these ACI code-related methods. Both due to advances in concrete technology and the popularity of high-strength concrete, significant cost reductions can be obtained through the use of thinner walls in high-rise structures. Thinner walls reduce the cost of buildings as well as increase the net liable space of a building. It is thus becoming increasingly important to carry out an accurate, less conservative, design of core walls (Fragomeni et al, 1995).

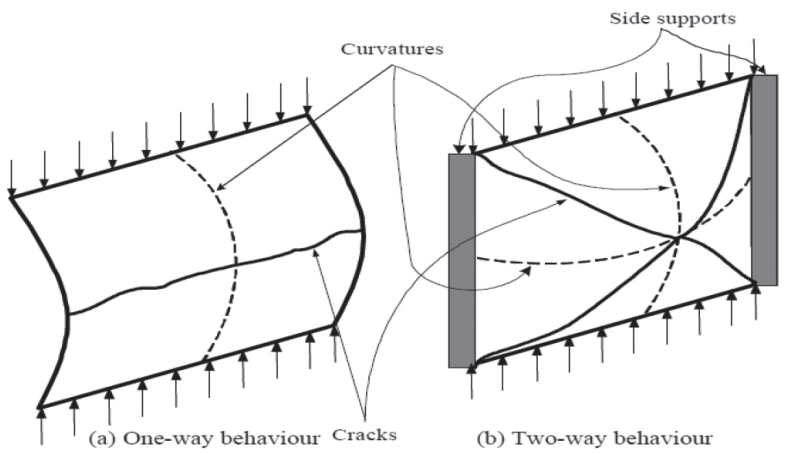

Fig. 1 Behaviour of axially loaded panels (Doh \& Fragomeni, 2005).

\section{MODELING OF MASONRY INFILL}

In the case of an infill wall located in a lateral load-resisting frame, the stiffness and strength contributions of the infill are considered by modeling the infill as an equivalent diagonal strut. The infill parameters are considered by Chethan et al, (2009):

$$
\alpha_{h}=\frac{\pi}{2 \lambda_{h}}
$$

where, ' $\lambda$ ' ' is an empirical parameter expressing the relative stiffness of the column to the infill and is given by

$$
\lambda_{h}=\sqrt[4]{\frac{E_{m} t \sin 2 \theta}{4 E_{c} I_{c} h}}
$$

Assuming $\alpha_{L=} \boldsymbol{\alpha}_{h}$ where $\alpha_{L}$ is a parameter for the contact length of a beam member with infill, the width ' $w$ ' of the equivalent diagonal strut is given by

$$
\begin{gathered}
w=\sqrt{\alpha_{L}{ }^{2}+\alpha_{h}{ }^{2}} \\
\boldsymbol{w}=1.414 \alpha_{h}
\end{gathered}
$$

where:

$E_{m}=$ Modulus of elasticity of the masonry infill

$t^{m}=$ Thickness of the masonry infill

$h=$ Height of the masonry infill

$E_{c}=$ Modulus of elasticity of the column

$I_{c}^{c}=$ Moment of inertia of the column

$\theta=$ Slope of the infill diagonal to the horizontal

\section{DESCRIPTION OF THE MODEL (CHETHAN ET AL. 2009)}

The structure is comprised of the following elements:

Foundations: Individual column footings

Columns: RC column of $75 \mathrm{~mm} \times 100 \mathrm{~mm}$.

Beams: RC beam of $75 \mathrm{~mm} \times 100 \mathrm{~mm}$.

Floor slab: RC slab of $50 \mathrm{~mm}$ thickness.

Grade of Concrete: M25

Figure 2(a) and Figure 2(b) show the dimensions and 3D RC model on a shake table.

Table 1. gives the material properties of the concrete, steel and bricks considered in the analysis.

Tab. 1 Material Properties.

\begin{tabular}{|l|l|l|l|}
\hline Material & Concrete & Steel & Bricks \\
\hline Modulus of elasticity $\mathbf{N} / \mathbf{m}^{2}$ & $2.5 \times 10^{10}$ & $2 \times 10^{11}$ & $14 \times 10^{6}$ \\
\hline Poissons ratio & 0.15 & 0.3 & 0.18 \\
\hline Density $\mathbf{k N} / \mathbf{m}^{3}$ & 25 & 78.6 & 19.2 \\
\hline
\end{tabular}

\section{LOADS}

The analysis of the structure was done using SAP 2000 software. The dead load and earthquake load are considered for the analysis.

\section{a) Dead load (DL)}

i) The dead load was considered as per IS 875-1987 (Part I-Dead loads)

ii) Unit weight of $\mathrm{RCC}=25 \mathrm{kN} / \mathrm{m}^{3}$

iii) Unit weight of Brick $=19.2 \mathrm{kN} / \mathrm{m}^{3}$ 


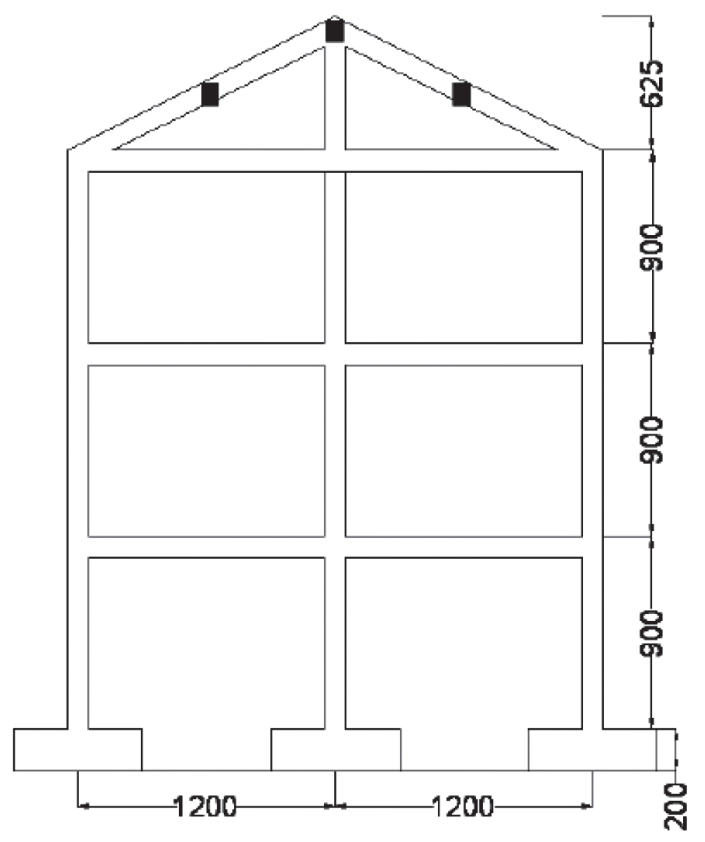

Fig. 2(a) Dimensions of 3D Model.

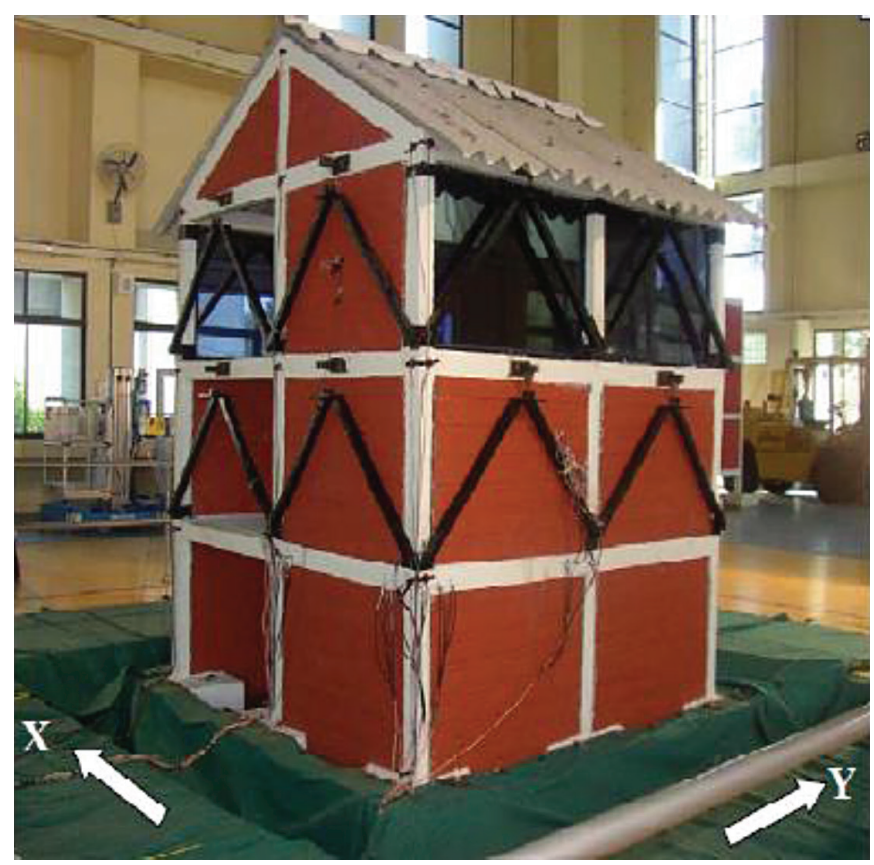

Fig. 2(b) 3D-RC structure on a shake table.

\section{b) Earthquake Load (EL)}

The earthquake load was considered as per IS 1893 (Part 1): 2002. The factors considered are:
i) Zone factors $=0.10,0.16,0.24,0.36$ (zone 2-zone 5)
ii) Importance factor $=1.0$
iii) Response reduction factor $=5.0$
iv) Soil condition $=$ Soft soil
v) Damping $=5 \%$

\section{c) Width of the Strut:}

The width of the strut for the model and prototype in both the Along the Gable Frame (AGF) and the Perpendicular to the Gable
Frame (PGF) directions were obtained using the formula proposed by Chethan et al. (2009) as shown in Table 2.

Tab. 2 Width of the diagonal strut.

\begin{tabular}{|l|l|l|l|}
\hline Type of structure & Model & Prototype in AGF & Prototype in PGF \\
\hline $\begin{array}{l}\text { Width of diagonal } \\
\text { strut }\end{array}$ & $0.396 \mathrm{~m}$ & $2.041 \mathrm{~m}$ & $2.006 \mathrm{~m}$ \\
\hline
\end{tabular}

\section{GENERATION OF TIME HISTORY AND RESPONSE SPECTRA}

The design response spectra was developed for Zones II, III, IV and $\mathrm{V}$ for the two axes and were fed into the Desired File Generator (DFG) software. The DFG software converts the required response spectrum into the time history, which is in terms of the acceleration terms. A typical response spectrum and time history is shown in Figure 3(a) and Figure 3(b) respectively.

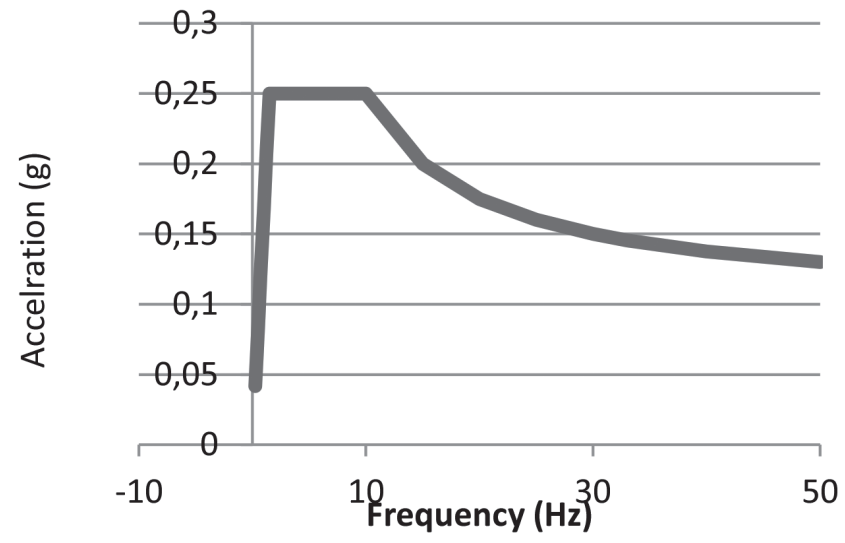

Fig. 3(a) Typical response spectrum.

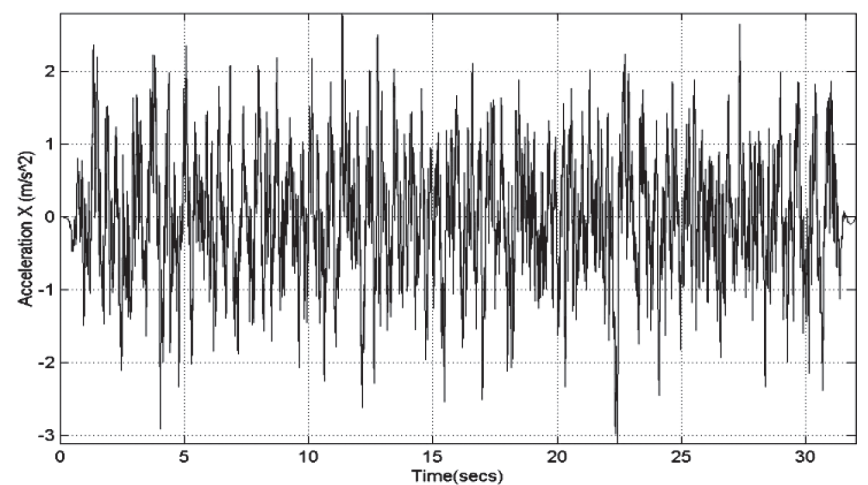

Fig. 3(b) Typical time history.

\section{RESULTS AND DISCUSSION}

\section{a) Validation of the Models}

A modal analysis of the 3D-RC frame was carried out, and the modal parameters, such as the natural frequencies and mode shapes, were obtained. The experimental results obtained from the shake table tests conducted at CPRI, Bangalore, were considered for the validation. The natural frequencies obtained by the modal analysis and shake table test for the 3D RC model are compared in Table 3. 
Tab. 3 Comparison of Natural Frequencies.

\begin{tabular}{|c|c|c|}
\hline \multicolumn{3}{|l|}{ MASONRY INFILL (Hz) } \\
\hline DIRECTION & SHAKE TABLE & $\begin{array}{l}\text { MODAL } \\
\text { ANALYSIS }\end{array}$ \\
\hline Along Gable Frame (AGF) & 10.75 & 9.89 \\
\hline $\begin{array}{l}\text { Perpendicular to Gable } \\
\text { Frame (PGF) }\end{array}$ & 6.00 & 5.81 \\
\hline
\end{tabular}

From Table 3, it can be seen that the natural frequencies obtained from the shake table tests and modal analysis match; hence, the models are validated.

\section{b) Natural Frequencies Along the Gable Frame's direction (AGF)}

The natural frequencies for the AGF direction obtained from the modal analysis for the model and the prototype of the 3D RC structure are tabulated in Table 4.

Tab. 4 Natural Frequencies (Hz).

\begin{tabular}{|c|c|c|}
\hline Models & MODEL & PROTOTYPE \\
\hline BF & 4.3124 & 2.033 \\
\hline MI & 9.8883 & 2.996 \\
\hline MW & 11.328 & 3.559 \\
\hline
\end{tabular}

MODEL (AGF)

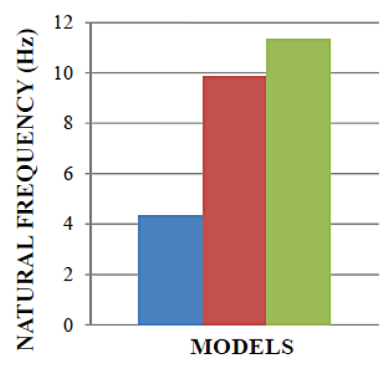

PROTOTYPE (AGF)

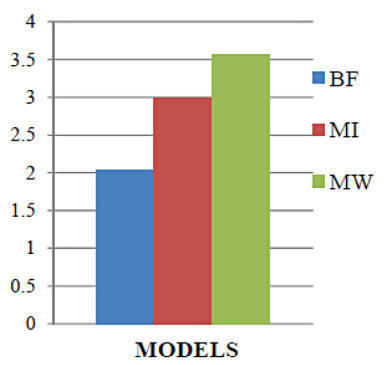

Fig. 4 Natural Frequencies (Hz).

Figure 4 shows the models versus the natural frequency graph for the AGF direction. This indicates that the MW has the highest natural frequency followed by the MI. The Bare Frame (BF) has the lowest natural frequency. The natural frequencies of the model for MI and MW increase by $56 \%$ and $62 \%$, and they increase by $32 \%$ and $43 \%$ respectively for the prototype.

\section{c) Natural Frequency Perpendicular to the Gable Frame (PGF)}

The natural frequencies for the PGF obtained from the modal analysis of the model and the 3D prototype of the RC structure are tabulated in Table 5.

Tab. 5 Natural Frequencies (Hz) PGF direction.

\begin{tabular}{|c|c|c|}
\hline Models & MODEL & ROTOTYPE \\
\hline BF & 3.42 & 1.11 \\
\hline MI & 5.81 & 1.66 \\
\hline MW & 7.20 & 2.09 \\
\hline
\end{tabular}

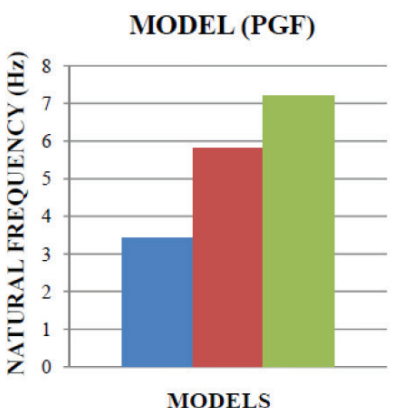

PROTOTYPE (PGF)

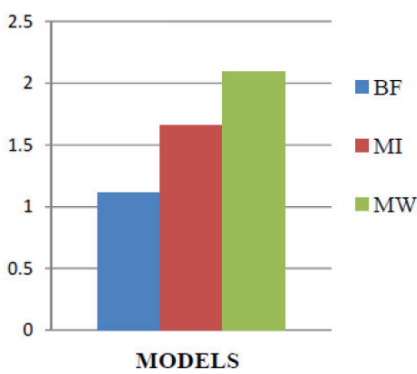

Fig. 5 Natural Frequencies (Hz) PGF direction.

Figure 5 shows the models versus the natural frequency graph for the PGF direction. This indicates that the BF has the lowest natural frequency. The MI and MW frequencies are more due to the additional stiffness of the structure. The natural frequencies of the models for MI and MW increase by $41 \%$ and $53 \%$ for prototype; they increase by $33 \%$ and $47 \%$ respectively.

\subsection{Results of response spectrum analysis}

The response spectra are generated for different seismic zones as specified by the IS 1893 (part 1):2002, and the analysis is done in Sap2000. The displacements and accelerations obtained from the Response Spectrum Analysis for Zone V are tabulated below.

\section{a) Displacement of AGF direction}

The Displacements of AGF obtained from the response spectrum analysis is tabulated in Table 6.

Tab. 6 Displacement (mm) AGF for Zone V.

\begin{tabular}{|c|c|c|c|}
\hline \multicolumn{4}{|c|}{ MODEL AGF } \\
\hline STOREY & BF & MI & MW \\
\hline $\mathbf{1}$ & 0.000 & 0.000 & 0.000 \\
\hline $\mathbf{2}$ & 2.496 & 0.194 & 0.038 \\
\hline $\mathbf{3}$ & 4.419 & 0.411 & 0.085 \\
\hline $\mathbf{4}$ & 6.215 & 1.362 & 0.735 \\
\hline \multicolumn{4}{|c|}{ PROTOTYPE AGF } \\
\hline $\mathbf{1}$ & 0.000 & 0.000 & 0.000 \\
\hline $\mathbf{2}$ & 33.270 & 4.824 & 1.260 \\
\hline $\mathbf{3}$ & 64.576 & 7.238 & 2.625 \\
\hline $\mathbf{4}$ & 105.932 & 44.585 & 25.294 \\
\hline
\end{tabular}

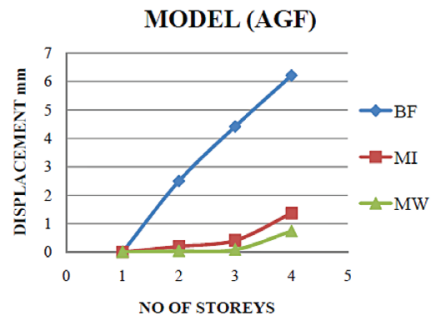

PROTOTYPE (AGF)

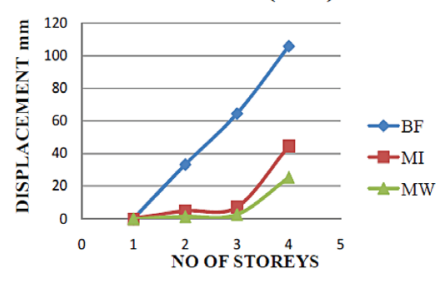

Fig. 6 Displacement (mm) AGF for Zone $V$. 
Figure 6 shows the graph of the displacements versus the number of storeys in the AGF direction. The displacement of the model for MI and MW is lower by $78 \%$ and $88 \%$, and it is lower by $58 \%$ and $76 \%$ respectively for the prototype compared to the $\mathrm{BF}$. This indicates that the MI and MW have minimum displacements because of greater stiffness. It has also been observed that the displacement values increase as the floor height increases. A rapid increase in displacement is seen in the top storey because of the openings.

\section{b) Displacement of PGF direction}

The displacements of the PGF obtained from the response spectrum analysis are tabulated in Table 7.

Tab. 7 Displacement (mm) PGF for Zone V.

\begin{tabular}{|c|c|c|c|}
\hline \multicolumn{4}{|c|}{ MODEL PGF } \\
\hline STOREY & BF & MI & MW \\
\hline $\mathbf{1}$ & 0.000 & 0.000 & 0.000 \\
\hline $\mathbf{2}$ & 4.044 & 0.099 & 0.016 \\
\hline $\mathbf{3}$ & 6.820 & 0.165 & 0.038 \\
\hline $\mathbf{4}$ & 9.300 & 2.288 & 1.340 \\
\hline \multicolumn{4}{|c|}{ PROTOTYPE AGF } \\
\hline $\mathbf{1}$ & 0.000 & 0.000 & 0.000 \\
\hline $\mathbf{2}$ & 130.946 & 2.623 & 0.805 \\
\hline $\mathbf{3}$ & 195.522 & 4.341 & 1.485 \\
\hline $\mathbf{4}$ & 282.646 & 107.313 & 68.332 \\
\hline
\end{tabular}
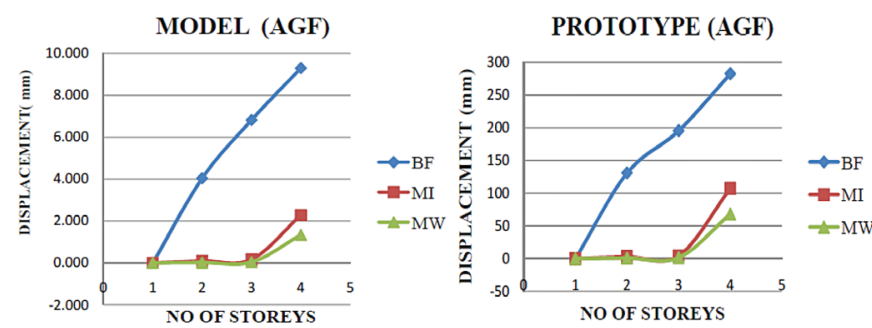

Fig. 7 Displacement (mm) PGF for Zone V.

Figure 7 shows the graph of the displacements versus the number of storeys in the PGF direction. The displacement of the models for MI and MW is lower by $75 \%$ and $86 \%$, and it is lower by $62 \%$ and $76 \%$ respectively for the prototype compared to the BF. The MI and MW are have lower values of AGF when compared to the PGF direction, because of the participation of the stiffness from MI and MW. From this it can be clearly understood that the displacement decreases as the stiffness increases. The displacement is almost $60 \%$ higher in the PGF direction.

\section{c) Acceleration of AGF direction}

The accelerations obtained for the AGF direction from the response spectrum analysis are tabulated in Table 8 .

Tab. 8 Acceleration $\left(\mathrm{m} / \mathrm{s}^{2}\right) A G F$ for Zone $V$.

\begin{tabular}{|c|c|c|}
\hline Models & MODEL & PROTOTYPE \\
\hline BF & 2.21 & 7.435 \\
\hline MI & 1.12 & 4.394 \\
\hline MW & 0.59 & 2.699 \\
\hline
\end{tabular}

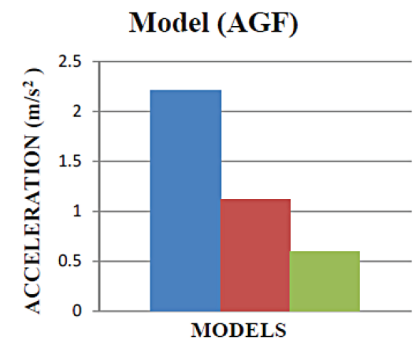

PROTOTYPE (AGF)

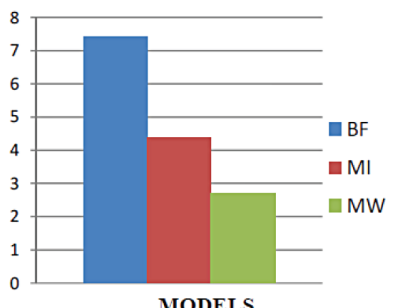

MODELS

Fig. 8 Acceleration $\left(\mathrm{m} / \mathrm{s}^{2}\right)$ of AGF for Zone $V$.

Figure 8 shows the models versus the acceleration graph of the AGF direction. The acceleration of the model for MI and MW have lower by $49 \%$ and $73 \%$ and for prototype, it is lower by $41 \%$ and $64 \%$ respectively compared to the $\mathrm{BF}$. This indicates that the MW has a lower acceleration value because of its mass.

\section{d) Acceleration of PGF direction}

The accelerations obtained for the PGF direction from the response spectrum analysis is tabulated in Table 9 .

Tab. 9 Acceleration $\left(\mathrm{m} / \mathrm{s}^{2}\right) P G F$ for Zone $V$.

\begin{tabular}{|c|c|c|}
\hline Models & MODEL & PROTOTYPE \\
\hline BF & 3.54 & 15.85 \\
\hline MI & 2.02 & 8.07 \\
\hline MW & 1.67 & 4.79 \\
\hline
\end{tabular}

MODEL (PGF)

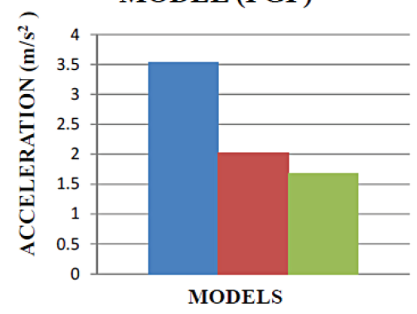

Fig. 9 Acceleration $\left(\mathrm{m} / \mathrm{s}^{2}\right)$ of PGF for Zone $\mathrm{V}$.

Figure 9 shows the models versus the acceleration graph for the PGF direction. The acceleration of the model for MI and MW is lower by $43 \%$ and $53 \%$; for the prototype, it is lower by $49 \%$ and $70 \%$ respectively compared to the $\mathrm{BF}$. This indicates that the MW has less of an acceleration value because of its mass. The BF has a high acceleration value followed by the MI. It can also be observed that the acceleration of the PGF is almost doubled when compared to the AGF direction, because of the mass participation. 


\subsection{Time history analysis results}

The time history is generated from the response spectrum as per IS 1893 (part 1):2002 using DFG software, and the analysis is done in SAP2000.

\section{a) Displacement of the AGF direction}

The displacements obtained by the AGF direction from the time history analysis are tabulated in Table 10 .

Tab. 10 Displacement (mm) AGF for Zone $V$.

\begin{tabular}{|c|c|c|c|}
\hline \multicolumn{5}{|c|}{ MODEL PGF } \\
\hline STOREY & BF & MI & MW \\
\hline $\mathbf{1}$ & 0 & 0 & 0 \\
\hline $\mathbf{2}$ & 27.456 & 1.979 & 0.342 \\
\hline $\mathbf{3}$ & 48.609 & 4.192 & 0.765 \\
\hline $\mathbf{4}$ & 68.365 & 13.892 & 6.615 \\
\hline \multicolumn{5}{|c|}{ PROTOTYPE AGF } \\
\hline $\mathbf{1}$ & 0 & 0 & 0 \\
\hline $\mathbf{2}$ & 49.905 & 6.7536 & 1.638 \\
\hline $\mathbf{3}$ & 96.864 & 10.133 & 3.412 \\
\hline $\mathbf{4}$ & 158.898 & 62.419 & 32.882 \\
\hline
\end{tabular}
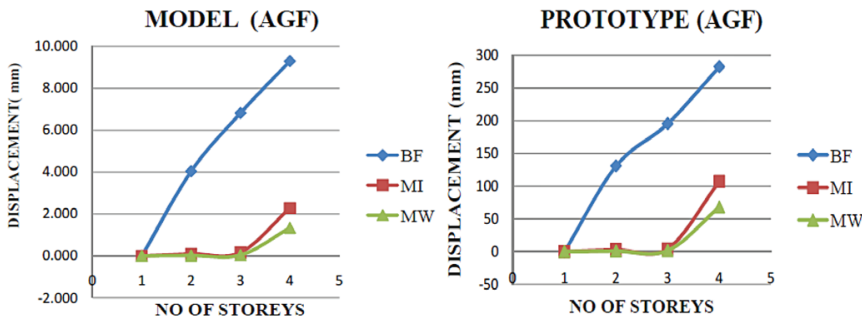

Fig. 10 Displacement ( $\mathrm{mm}$ ) of AGF for Zone $V$.

Figure 10 shows the graph of the displacements versus the number of storeys in the AGF direction from the time history analysis. The displacement of the model for MI and MW is lower by $80 \%$ and $90 \%$, and for prototype it is lower by $61 \%$ and $79 \%$ respectively compared to the BF. This indicates that the MI and MW have lower displacements because of a higher stiffness. The BF has a high value of displacement because of less stiffness. It is also observed that the displacement values increase as the floor height increases.

\section{b) Displacement of the PGF direction}

The displacements obtained in the PGF direction from the time history analysis for Zone $\mathrm{V}$ is tabulated in Table 11.

Figure 11 shows the graph of the displacements versus the number of storeys in the PGF direction from the time history analysis. The displacement of the model for MI and MW decreases by $67 \%$ and $84 \%$, and it decreases by $56 \%$ and $76 \%$ respectively for the prototype compared to the BF. This indicates that the BF has a high displacement because of less stiffness. The MI and MW have lower displacement values because of the high degree of stiffness.

Tab. 11 Displacement (mm) of PGF for Zone $V$.

\begin{tabular}{|c|c|c|c|}
\hline \multicolumn{5}{|c|}{ MODEL PGF } \\
\hline STOREY & BF & MI & MW \\
\hline $\mathbf{1}$ & 0 & 0 & 0 \\
\hline $\mathbf{2}$ & 27.456 & 1.979 & 0.342 \\
\hline $\mathbf{3}$ & 48.609 & 4.192 & 0.765 \\
\hline $\mathbf{4}$ & 68.365 & 13.892 & 6.615 \\
\hline \multicolumn{4}{|c|}{ PROTOTYPE AGF } \\
\hline $\mathbf{1}$ & 0 & 0 & 0 \\
\hline $\mathbf{2}$ & 49.905 & 6.7536 & 1.638 \\
\hline $\mathbf{3}$ & 96.864 & 10.133 & 3.412 \\
\hline $\mathbf{4}$ & 158.898 & 62.419 & 32.882 \\
\hline
\end{tabular}
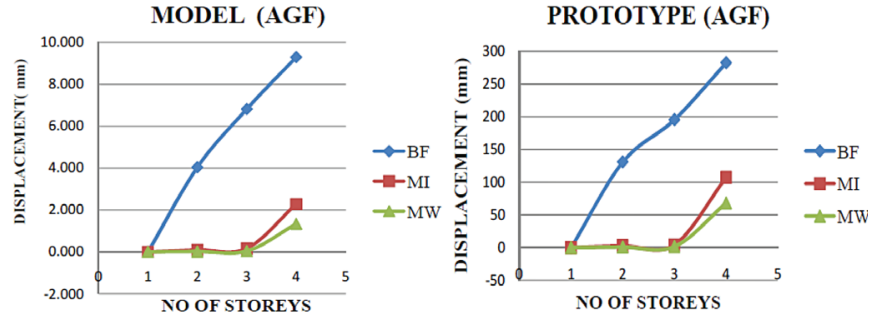

Fig. 11 Displacement ( $\mathrm{mm}$ ) of PGF for Zone $\mathrm{V}$.

\section{c) Acceleration of the AGF direction}

The accelerations obtained by the AGF direction from the time history analysis for Zone $\mathrm{V}$ is tabulated in Table 12.

Tab. 12 Acceleration $\left(\mathrm{m} / \mathrm{s}^{2}\right)$ of AGF for Zone $V$.

\begin{tabular}{|c|c|c|}
\hline Models & MODEL & PROTOTYPE \\
\hline BF & 14.405 & 48.238 \\
\hline MI & 9.248 & 34.034 \\
\hline MW & 5.515 & 25.371 \\
\hline
\end{tabular}

PROTOTYPE AGF

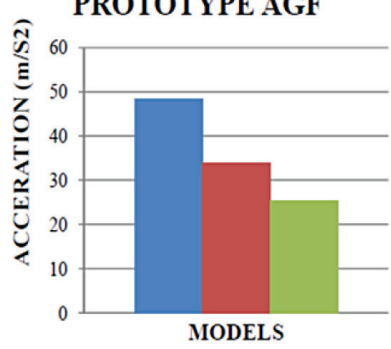

Fig. 12 Acceleration $\left(\mathrm{m} / \mathrm{s}^{2}\right)$ of $A G F$ for Zone $V$.

Figure 12 shows the models versus the acceleration graph of the AGF direction. The acceleration of the models for MI and MW is lower by $36 \%$ and $62 \%$; for the prototype, it is lower by $29 \%$ and $47 \%$ respectively compared to the BF. This indicates that the MW has less of an acceleration value because of its mass. BF has a high acceleration value followed by the MI. 


\section{d) Acceleration of the PGF direction}

The acceleration obtained in the PGF direction from the time history analysis for Zone $\mathrm{V}$ is tabulated in Tab. 13.

Tab. 13 Acceleration $\left(\mathrm{m} / \mathrm{s}^{2}\right) P G F$ for Zone $V$.

\begin{tabular}{|c|c|c|}
\hline Models & MODEL & PROTOTYPE \\
\hline BF & 21.384 & 95.16 \\
\hline MI & 19.534 & 75.895 \\
\hline MW & 15.071 & 43.182 \\
\hline
\end{tabular}
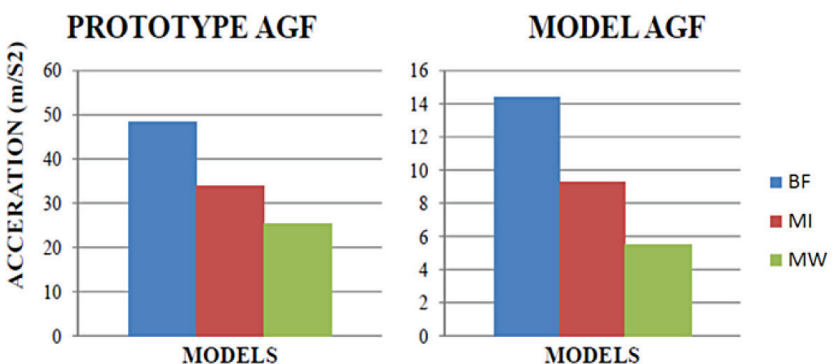

Fig. 13 Acceleration $\left(\mathrm{m} / \mathrm{s}^{2}\right)$ of PGF for Zone $V$.

Figure 13 shows the models versus the acceleration graph in the AGF direction. The acceleration of the models for MI and MW is lower by $9 \%$ and $30 \%$, and it is lower by $20 \%$ and $55 \%$ respectively for the prototype compared to the BF. This indicates that the MW has less of an acceleration value because of its mass. The BF has a high acceleration value followed by the MI. The acceleration is almost doubled in the case of the PGF when compared to the AGF.

\section{CONCLUSIONS}

1. The results of the modal analysis carried out on the FE model of the 3D-RC structure with the masonry infill matches well with the shake table test results and hence is validated.

2. The natural frequencies of the model for MI and MW increases by $56 \%$ and $62 \%$ AGF and $41 \%$ and $53 \%$ PGF compared to BF.

3. The natural frequencies of the prototype for MI and MW increase by $32 \%$ and $43 \%$ AGF and $33 \%$ and $47 \%$ PGF compared to BF.

4. The response spectrum analysis was carried out on the model and prototype of the 3D-RC structure as per IS 1893 (part I):2002, and the results were tabulated. Here, it is observed that the displacement PGF is almost twice that of the AGF for all the cases showing the effect of the first modal frequency.

5. The displacement of the model for MI and MW is lower by $78 \%$ and $88 \%$ AGF and $75 \%$ and $86 \%$ PGF compared to BF; this highlights the role of the stiffness.

6. The displacement of the prototype for MI and MW is lower by $58 \%$ and $76 \%$ AGF and $62 \%$ and $76 \%$ PGF compared to BF.

7. The acceleration of the model for MI and MW is lower by $49 \%$ and $73 \% \mathrm{AGF}$ and $43 \%$ and $53 \%$ PGF compared to BF.

8 . The acceleration of the prototype for $\mathrm{MI}$ and $\mathrm{MW}$ is lower by $41 \%$ and $64 \%$ AGF and $49 \%$ and $70 \%$ PGF compared to BF.
9. The time history analysis was carried out on the model and prototype of the 3D-RC structure as per IS 1893 (part I):2002, and the results were tabulated. Here it is also observed that the displacement PGF is almost twice that of the AGF for all the cases showing the effect of the first modal frequency.

10. The displacement of the model for MI and MW is lower by $80 \%$ and $90 \%$ AGF and $67 \%$ and $84 \%$ PGF respectively compared to BF.

11. The displacement of the prototype for MI and MW is lower by $61 \%$ and $79 \%$ AGF and $56 \%$ and $76 \%$ PGF compared to BF.

12. The acceleration of the model for MI and MW is lower by $36 \%$ and $62 \%$ AGF and $9 \%$ and $30 \%$ PGF compared to BF.

13. The acceleration of the prototype for MI and MW decreases by $29 \%$ and $47 \%$ AGF and $20 \%$ and $55 \%$ PGF compared to $\mathrm{BF}$.

14. Due to the openings and absence of a central column in the top storey, the displacement rapidly increases and is almost four times that of the lower storey.

15. By comparing the results of the response spectrum and time history analyses for all the cases of both the model and prototype, it can be concluded that FE analysis is an effective tool for the dynamic analysis of 3D RC structures.

16. The results clearly highlight that although masonry infill does not interfere in a vertical load-resisting system for the RC frame structures, it significantly affects its lateral load-resisting system.

17. The MW offers a high degree of stiffness to mass ratio compared to the MI and hence can be effectively used as a lateral load-resisting system.

18. When comparing the results of the response spectrum and time history analysis for all the cases, it can be observed that the results of the time history analysis are higher. This shows the effectiveness of the time history analysis. 


\section{REFERENCES}

AS3600-2001, Concrete Structures, Standards Australia, Sydney, Australia 2001

BS8110-1997, Structural Use of Concrete, Part 1 - Code of Practice for Design and Construction, British Standards Institution, London, 1997.

Chethan K, R. Ramesh Babu, Katta Venkataramana and Akanshu Sharma (2009), "Studies on Dynamic Characteristics of $3 D$ Reinforced Concrete Frame with masonry Infill," Journal of CPRI, Vol 5 (2).

Doh, J. H. and Fragomani, S. (2005), "Evaluation of Experimental Work on Concrete Walls in One and Two-way Action," Australian Journal of Structural Engineering, Vol 6, No 1, pp 37-52.

Doh, J. H., Lee, D. J., Guan, H., and Loo, Y. C., (2008), “Concrete Wall with Various Support Conditions" The 4th International Conference on Advances in Structural Engineering and Mechanics (ASEM'08), CD ROM Proceeding, Jeju, Korea, May 26-28, 2008, pp. 967-975.

Doh, J. H. (2002), "Experimental and theoretical studies of normal and high strength concrete wall panels," $\mathrm{PhD}$ Thesis, Griffith University, Gold Coast, Australia 2002.

Fragomeni et al. (1995), "Concrete walls with and without openings supported on three sides", National Library of Australia.

Fragomeni, S. and Mendis, P. A. (1999), "Applicability of Current ACI318 Wall Design Formula for High Strength Concrete Walls, " Advances in Structural Engineering - International Journal, 2 (2): 103-108.

Fragomeni, S. (1995), "Design of normal and high strength reinforced concrete walls," $\mathrm{PhD}$ Thesis, University of Melbourne, Australia 1995.

Kripanarayanan, K. M. (1977), "Interesting Aspect of the Empirical Wall Design Equation," ACI Structural Journal, Vol. 74, No. 5, May 1977, pp. 204-207.
Md Khaja Moniuddin et al. (2013), "Earthquake analysis on $2 D$ $R C$ frames with different aspect ratios of masonry infill and monolithic panel," IJRET: International Journal of Research in Engineering and Technology eISSN: 2319-1163 pISSN: 23217308, pp. 18-23.

Oberlender, G. D. (1973), "Strength investigation of reinforced concrete load bearing wall panels, " Ph.D thesis, University of Texas, Arlington.

P. G. Asteris and D. M. Cotsovos, (2012), "Numerical Investigation of the Effect of Infill Walls on the Structural Response of RC Frames, " he Open Construction and Building Technology Journal, 2012, 6,(Suppl 1-M11) 164-181

Pillai, S. U. and Parthasarathy, C. V, (1977), "Ultimate Strength and Design of Concrete Walls, Building and Environment, " London, 12: 25-29.

Saheb, S. M., \& Desayi, P. (1989), "Ultimate Strength of $R C$ Wall Panels in One-Way In-Plane Action, " Journal of Structural Engineering, 115(10): $2617-2617$.

Seddon, A. E. (1956), "The strength of concrete walls under axial and eccentric loads, "Symposium on Strength of Concrete Structures, Cement and Concrete Association, May, London.

T. Paulay, M. Priestley (1992), "Seismic Design of Reinforced Concrete and Masonry Buildings, ” A Wiley Interscience Publication.

Zielinski, Z.A., Troitski, M. S. and Christodoulou, H. (1982), "Fullscale Bearing Strength Investigation of Thin Wall-Ribbed Reinforced Concrete Panels, " ACI Journal, 79: 313-321.

Zielinski, Z. A., Troitski, M. S. and El-Chakieh, E. (1983), "Bearing Capacity Tests on Precast Concrete Thin-Wall Ribbed Panels, " Prestressed Concrete Institute Journal, Chicago, 28 (3): 89-103. 